http://dx.doi.org/10.32929/2446-8355.2019v28n4p461-477

\title{
POTENCIAL FISIOLÓGICO DE SEMENTES DE CULTIVARES DE AVEIA BRANCA PRODUZIDAS EM DIFERENTES LOCAIS DE CULTIVO
}

\author{
Diogo Gomes ${ }^{1}$, Moryb Jorge Lima da Costa Sapucay ${ }^{2 *}$, Ailton Luiz Passador ${ }^{1}$, José Henrique \\ Bizzarri Bazzo ${ }^{3}$, Denis Santiago da Costa $^{4}$, Claudemir Zucareli ${ }^{3}$
}

\footnotetext{
${ }^{1}$ Mestrando em Fitotecnia, Departamento de Agronomia, Universidade Estadual de Londrina, Londrina-PR.

${ }^{2}$ Doutorando em Fitotecnia, Departamento de Agronomia, Universidade Estadual de Londrina, Londrina-PR.

*E-mail do autor correspondente: moryb_sapucay@hotmail.com

${ }^{3}$ Professor Adjunto, Departamento de Agronomia, Universidade Estadual de Londrina, Londrina-PR.

${ }^{4}$ Professor do Instituto Federal de Educação, Ciência e Tecnologia de Mato Grosso do Sul, Campus Nova Andradina-MS.
}

\section{Recebido: 11/07/2018; Aceito: 19/12/2019}

RESUMO: As condições edafoclimáticas do ambiente de cultivo influenciam diretamente o crescimento e o desenvolvimento da planta e, consequentemente, a produtividade e a qualidade das sementes. Neste sentido, objetivou-se avaliar o potencial fisiológico de sementes de aveia branca granífera produzidas em ambientes com diferentes características edafoclimáticas. O delineamento experimental foi o inteiramente casualizado em esquema fatorial $3 \times 8$, com quatro repetições. Os tratamentos constaram de três ambientes de cultivo no estado do Paraná (Londrina, Mauá da Serra e Ponta Grossa) e oito cultivares (IPR Afrodite, IPR Artemis, URS Taura, URS Tarimba, URS Charrua, URS Corona, URS Guará e URS Altiva). Foram avaliados: germinação, primeira contagem da germinação, comprimento e massa seca de plântula, índice de velocidade de emergência, emergência de plântulas em areia, envelhecimento acelerado e condutividade elétrica. Londrina, Ponta Grossa e Mauá da Serra apresentam potencial para a produção de sementes de aveia branca granífera, resultando em sementes com germinação acima dos padrões de comercialização da espécie. O cultivo em Londrina resulta na produção de sementes de elevado vigor para todas as cultivares analisadas. Já em Ponta Grossa, as sementes de melhor qualidade foram produzidas pelas cultivares URS Taura, URS Corona e URS Guará, e em Mauá da Serra pela cultivar URS Altiva.

Palavras-chave: Avena Sativa L. Germinação. Vigor. Interação genótipo x ambiente.

\section{PHYSIOLOGICAL POTENTIAL OF SEEDS OF WHITE OAT CULTIVARS PRODUCED IN DIFFERENT CULTURAL ENVIRONMENTS}

\begin{abstract}
The edaphoclimatic conditions of the growing environment directly influence the growth and development of plant and, consequently, the productivity and seeds quality. In this sense, the aim was to evaluate the physiological potential of seeds of different cultivars of graniferous white oats produced in environments with different edaphoclimatic characteristics. The experimental design was completely randomized in a $3 \times 8$ factorial scheme, with four replications. The treatments consisted of three cultivation environments in
\end{abstract}


the state of Paraná (Londrina, Mauá da Serra and Ponta Grossa) and eight cultivars (IPR Afrodite, IPR Artemis, URS Taura, URS Tarimba, URS Charrua, URS Corona, URS Guará and URS Altiva). Were evaluated: germination, first count of the germination test, length and dry mass of the seedlings, emergency speed index, seedling emergence in sand, accelerated aging and electrical conductivity. Londrina, Ponta Grossa and Mauá da Serra present potential for production of graniferous white oat seeds with germination above the commercialization standards of the species. Londrina cultivation results in the production of high vigor seeds for all cultivars analyzed. In Ponta Grossa, the best quality seeds were produced by URS Taura, URS Corona and URS Guará, and in Mauá da Serra by URS Altiva.

Key words: Avena sativa L. Germination. Vigor. Genotype x environment interaction.

\section{INTRODUÇÃO}

A aveia branca (Avena sativa L.) é um cereal de inverno que se destaca por possuir múltiplos propósitos, sendo destinado à alimentação humana e animal, além de ser matériaprima para as indústrias cosmética e química (DE MORI et al., 2012). Os grãos e seus derivados são fonte de proteínas, lipídios, vitaminas, minerais e fibras (BUTT et al., 2008), classificando-o como alimento funcional, com inúmeros benefícios a saúde humana (ANDON; ANDERSON, 2008).

No Brasil, a demanda e a produção dessa gramínea têm crescido nos últimos anos, sendo o Paraná um dos principais estados produtores (CONAB, 2017). Visando atender a expansão das áreas de cultivo e a necessidade de aumento de produtividade, é indispensável a produção e utilização de sementes de elevada qualidade que proporcionem maior velocidade de emergência de plântulas em campo e, consequentemente, plantas com maior taxa de crescimento e desenvolvimento (LUDWIG et al., 2009).

Sementes de elevada qualidade têm a capacidade de gerar plantas normais e estabelecer campos uniformes, com ausência de doenças, mesmo sob condições climáticas adversas (MARCOS FILHO, 2015). Höfs et al. (2004), avaliando o impacto da qualidade fisiológica de sementes de arroz sobre o rendimento de grãos, verificaram que o uso de sementes de alto potencial fisiológico ocasionou aumento de $10 \%$ na produtividade, quando comparado a utilização de sementes de baixa qualidade fisiológica.

As cultivares possuem características genéticas distintas, que estão relacionadas à base genética proveniente do cruzamento dos parentais, as quais devem ser consideradas na seleção dos progenitores para a obtenção de sementes com elevado potencial fisiológico (NERLING, 2013).

A expressão gênica entre as diferentes cultivares interferem diretamente na produtividade e na qualidade de sementes. Tais características são fortemente influenciadas pelas condições climáticas do local de produção (CRESTANI et al., 2010), gerando, portanto, a necessidade de avaliação de aptidão dos ambientes para produção de sementes de cultivares específicas. 
Em função da época e do local de cultivo, determinadas características de ambiente como temperatura, disponibilidade hídrica e radiação solar exercem influência direta no crescimento e desenvolvimento das plantas, na formação, composição, rendimento e, consequentemente, no potencial fisiológico e tecnológico das sementes (SOUZA et al., 2009). O ambiente de cultivo, bem como sua interação com o genótipo, também pode influenciar a formação da semente e determinar sua qualidade, conforme proporciona melhores ou piores condições climáticas durante a maturação das plantas (GOMES et al., 2012).

Trabalhos que relacionam os efeitos da interação genótipo x ambiente sobre a qualidade fisiológica de sementes de aveia branca granífera são escassos, demonstrando a necessidade de realização de mais estudos que resultem em recomendações adequadas de técnicas de manejo para produção de sementes com alta qualidade.

Neste sentido, objetivou-se avaliar o potencial fisiológico de sementes de diferentes cultivares de aveia branca granífera cultivadas em ambientes com diferentes características edafoclimáticas.

\section{MATERIAL E MÉTODOS}

Foram utilizadas sementes de oito cultivares de aveia branca granífera, presentes entre as mais semeadas no Brasil, as quais foram obtidas do Ensaio Brasileiro de Cultivares de Aveia, realizado pelo Instituto Agronômico do Paraná - IAPAR. As sementes foram produzidas em três locais de cultivo no estado do Paraná com diferentes condições climáticas.

Os solos dos locais de cultivo Londrina e Mauá da Serra são classificados como Latossolo Vermelho distroférrico e em Ponta Grossa como Latossolo Vermelho distrófico (BHERING; SANTOS, 2008).

Os dados de temperaturas máxima, média e mínima e precipitação pluvial do período de cultivo nos três ambientes, estão apresentados na Figura 1.

Segundo a classificação de Köppen o clima característico de Londrina é tipo Cfa, descrito como subtropical úmido mesotérmico, com verões quentes, geadas pouco frequentes e chuvas que tendem a se concentrar nos meses de verão, sem estação seca definida. Em Mauá da Serra e Ponta Grossa, o clima é tipo Cfb, descrito como temperado mesotérmico com verões amenos, chuvas uniformemente distribuídas, sem estação seca e com geadas severas e frequentes. Em Londrina o experimento foi conduzido nas coordenadas $23^{\circ} 22^{\prime} \mathrm{S}$ e $51^{\circ} 10^{\prime} \mathrm{O}$, com altitude de $585 \mathrm{~m}$. Em Mauá da Serra o campo experimental estava localizado à $23^{\circ} 54^{\prime}$ $\mathrm{S}$ e $51^{\circ} 13^{\prime} \mathrm{O}$, com altitude de $1020 \mathrm{~m}$, e em Ponta Grossa à $25^{\circ} 10^{\prime} \mathrm{S}$ e $50^{\circ} 01^{\prime} \mathrm{O}$, com altitude de $880 \mathrm{~m}$.

As semeaduras foram realizadas mecanicamente nos dias 13/05/2016, 07/07/2016 e 04/05/2016 em Mauá da Serra, Ponta grossa, e Londrina, respectivamente, com densidade de 300 sementes viáveis $\mathrm{m}^{-2}$. As parcelas foram compostas por seis linhas de cinco metros de comprimento e espaçamento entre linhas de $0,17 \mathrm{~m}$, com área útil de $5,1 \mathrm{~m}^{2}$, em todos os locais. 

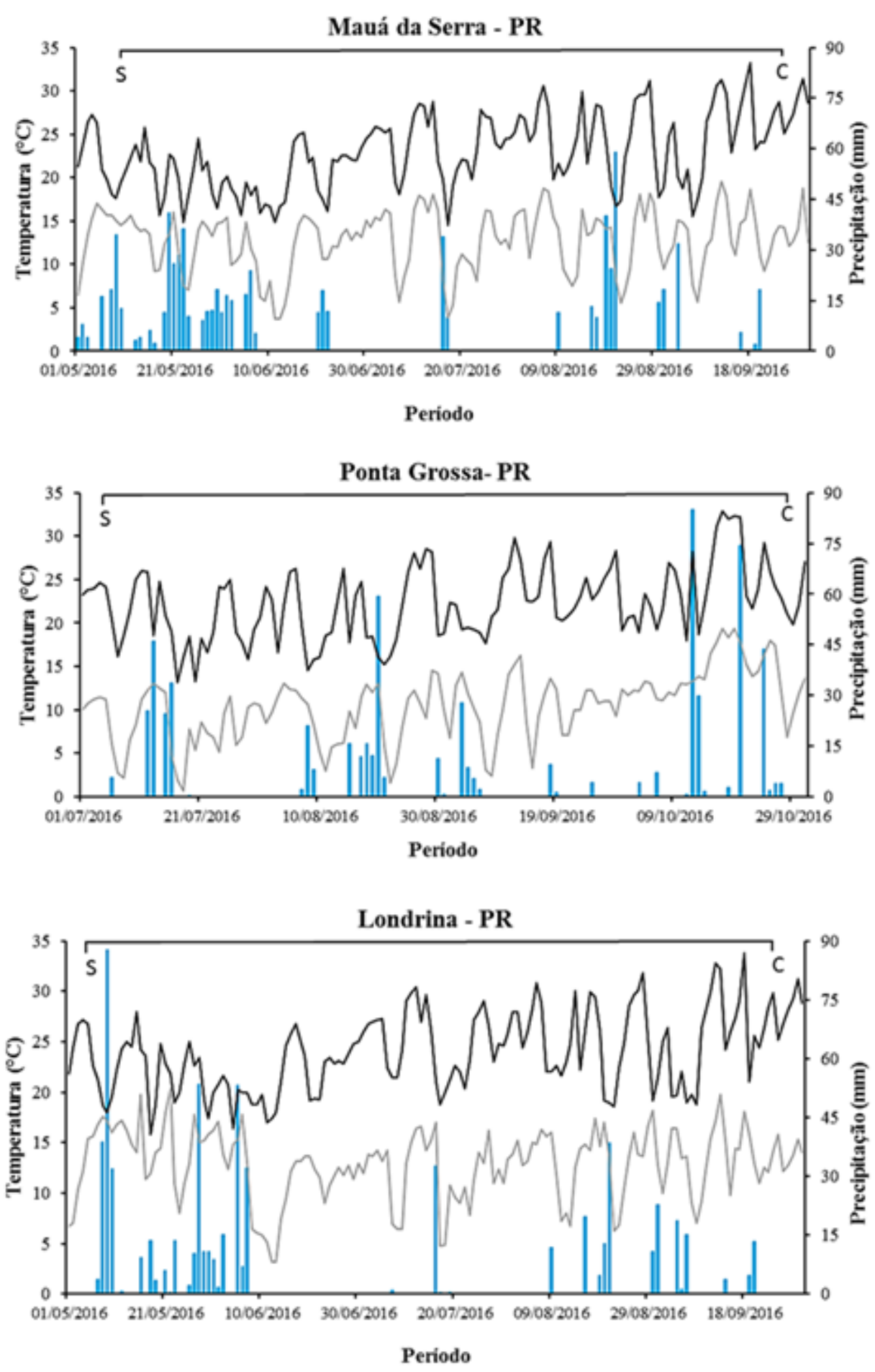

Figura 1. Temperaturas diárias $\left({ }^{\circ} \mathrm{C}\right)$ máxima e mínima e precipitação pluvial para as cidades de Mauá da Serra, Ponta Grossa e Londrina, durante o período de condução dos experimentos. S: semeadura; C: colheita. Maximum and minimum daily temperature and precipitation for the cities of Mauá da Serra, Ponta Grossa and Londrina, for the period of conduction of the experiment. S: sowing; $C$ : harvesting.

Fonte: Adaptado das estações meteorológicas do Instituto Agronômico do Paraná - IAPAR (2016). Source: Adapted from the weather stations of the Instituto Agronômico do Paraná - IAPAR (2016). 
No momento da semeadura foi realizada a adubação de base utilizando $10 \mathrm{~kg} \mathrm{ha}^{-1}$ de $\mathrm{N}$, $75 \mathrm{~kg} \mathrm{ha}^{-1}$ de $\mathrm{P}_{2} \mathrm{O}_{5}$ e $25 \mathrm{~kg} \mathrm{ha}^{-1}$ de $\mathrm{K}_{2} \mathrm{O}$ no município de Londrina; $8 \mathrm{~kg} \mathrm{ha}^{-1}$ de $\mathrm{N}, 60 \mathrm{~kg} \mathrm{ha}{ }^{-1}$ de $\mathrm{P}_{2} \mathrm{O}_{5}$ e $20 \mathrm{~kg} \mathrm{ha}^{-1}$ de $\mathrm{K}_{2} \mathrm{O}$ no município de Mauá da Serra e $12 \mathrm{~kg} \mathrm{ha}^{-1}$ de $\mathrm{N}, 90 \mathrm{~kg} \mathrm{ha}^{-1}$ de $\mathrm{P}_{2} \mathrm{O}_{5}$ e $30 \mathrm{~kg} \mathrm{ha}^{-1}$ de $\mathrm{K}_{2} \mathrm{O}$ no município de Ponta Grossa, com o formulado 4-30-10 em todos os ambientes de cultivo.

O delineamento experimental utilizado foi inteiramente casualizado em esquema fatorial $3 \times 8$, com quatro repetições. Os tratamentos constaram de três locais de cultivo (Londrina, Mauá da Serra e Ponta Grossa) e oito cultivares de aveia branca granífera (IPR Afrodite, IPR Artemis, URS Taura, URS Tarimba, URS Charrua, URS Corona, URS Guará e URS Altiva).

O manejo e tratos culturais foram realizados conforme a necessidade e recomendações para a cultura (LÂNGARO; CARVALHO, 2014). A colheita foi realizada após as sementes atingirem a maturação de colheita, estádio caracterizado pelo endurecimento da cariopse, plantas com aspecto seco e sementes com umidade abaixo de $20 \%$. Em seguida, as sementes foram armazenadas em câmara fria com ambiente controlado. Para a determinação da qualidade fisiológica das sementes foram realizadas as seguintes avaliações:

Teste de germinação: realizado com oito repetições de 50 sementes distribuídas em rolo de papel (germitest ${ }^{\circledR}$ ), umedecido com água destilada na proporção de 2,5 vezes a massa do papel seco. Os rolos de papel foram mantidos em germinador sob temperatura de $20^{\circ} \mathrm{C}$. A avaliação constou de duas contagens, aos cinco dias (primeira contagem) e aos dez dias (segunda contagem) após a instalação do teste, computando-se a porcentagem de plântulas normais (BRASIL, 2009).

Comprimento de plântulas: foi realizado a partir da semeadura de quatro repetições de 20 sementes, no terço superior da folha de papel germitest ${ }^{\circledR}$, umedecido com água destilada, na proporção de 2,5 vezes a massa do papel seco. Os rolos de papel contendo as sementes permaneceram por cinco dias em germinador, à temperatura de $20^{\circ} \mathrm{C}$, quando foi avaliado o comprimento das plântulas normais, com auxílio de uma régua milimetrada (NAKAGAWA, 1999). Os resultados foram expressos em centímetros por plântula.

Massa seca de plântulas: foi conduzido juntamente com o teste de comprimento de plântulas. As plântulas normais foram colocadas em embalagens de papel e levadas à estufa com circulação de ar forçada, regulada à temperatura de $80^{\circ} \mathrm{C}$, durante 24 horas (NAKAGAWA, 1999). Transcorrido o tempo, a massa seca foi mensurada em balança com precisão de 0,0001 g. Os resultados foram expressos em miligramas por plântula.

Emergência de plântulas em areia: o teste foi realizado com quatro repetições de 50 sementes por tratamento. A areia foi previamente lavada e, em seguida, disposta em bandejas plásticas. A semeadura foi realizada a $3,0 \mathrm{~cm}$ de profundidade. $O$ teste foi conduzido em casa de vegetação do tipo Van der Hoeven e a umidade mantida com irrigações de acordo com a necessidade da cultura. A avaliação do número de plântulas emergidas foi realizada no décimo quinto dia e os resultados expressos em porcentagem.

Índice de velocidade de emergência (IVE) de plântulas: foi realizado juntamente com o teste de emergência de plântulas em areia por meio de contagens diárias do número de 
plântulas normais. O cálculo do IVE foi realizado segundo a fórmula proposta por Maguire (1962).

Envelhecimento acelerado: foi realizado com quatro repetições em caixas tipo gerbox, com compartimento individual, contendo $40 \mathrm{~mL}$ de água em seu interior, e uma tela de alumínio, sobre a qual foram distribuídas uniformemente 240 sementes por gerbox. As caixas foram mantidas em câmara de envelhecimento acelerado, a $42^{\circ} \mathrm{C}$, durante 48 horas (MARCOS FILHO, 1999). Decorrido o tempo, foi instalado o teste de germinação sob temperatura de $20^{\circ} \mathrm{C}$ (BRASIL, 2009). A contagem do número de plântulas normais foi realizada cinco dias após a instalação do teste e os resultados expressos em porcentagem.

Condutividade elétrica: foi conduzido por meio do sistema de massa, com quatro repetições de 50 sementes. Foi determinada a massa das sementes e, estas colocadas em copos plásticos com $75 \mathrm{ml}$ de água deionizada e mantidas em B.O.D a $25^{\circ} \mathrm{C}$. Após 24 horas de embebição foi determinada a condutividade elétrica da solução com resultados expressos em $\mu \mathrm{S} \mathrm{cm}^{-1} \mathrm{~g}^{-1}$ (VIEIRA; KRZYZANOWSKI, 1999).

Os dados foram submetidos às análises de normalidade e homocedasticidade e, posteriormente, à análise de variância. As médias do fator local foram comparadas pelo teste de Tukey e as médias do fator cultivar pelo teste de Scott e Knott, a 5\% de probabilidade.

\section{RESULTADOS E DISCUSSÃO}

Houve efeito de interação entre os fatores cultivar e local de cultivo para as variáveis porcentagem de germinação, primeira contagem da germinação, comprimento e massa seca de plântula, índice de velocidade de emergência, envelhecimento acelerado e condutividade elétrica. A emergência de plântulas em areia apresentou efeito isolado de local (Tabela 1).

Tabela 1. Resumo da análise de variância referente à porcentagem de germinação (PG), primeira contagem da germinação (PC), comprimento de plântula (CPL), massa seca de plântula (MSPL), índice de velocidade de emergência (IVE), emergência de plântula em areia (EP), envelhecimento acelerado (EA) e condutividade elétrica (CE) de sementes de aveia branca granífera, em função da cultivar e do local de produção. Summary of the analysis of variance regarding the percentage of germination $(P G)$, first germination count $(P C)$, length of seedling (CPL), dry mass of seedlings (MSPL), emergency speed index (IVE), emergence of seedling in sand (EP), accelerated aging (EA) and electrical conductivity (EC), in seed lots of graniferous white oats, according to the cultivar and place of production.

\begin{tabular}{cccccccccc}
\hline \multicolumn{10}{c}{ Quadrado médio } \\
\hline FV & GL & PG & PC & CPL & MSPL & EP & IVE & EA & CE \\
\hline Local (L) & 2 & $171,80^{* *}$ & $470,57^{* *}$ & $369,80^{* *}$ & $19729,40^{* *}$ & $70,29^{* *}$ & $2,57^{* *}$ & $371,01^{* *}$ & $4479,96^{* *}$ \\
Cultivar (C) & 7 & $16,92^{* *}$ & $27,12^{*}$ & $17,70^{* *}$ & $1658,36^{* *}$ & $9,23^{\text {ns }}$ & $0,86^{* *}$ & $2290,97^{* *}$ & $748,41^{* *}$ \\
L x C & 14 & $60,64^{* *}$ & $89,43^{* *}$ & $21,22^{* *}$ & $840,99^{* *}$ & $9,19^{\text {ns }}$ & $0,29^{*}$ & $857,65^{* *}$ & $150,26^{*}$ \\
Erro & 72 & 5,06 & 11,27 & 1,64 & 219,95 & 8,70 & 0,16 & 24,03 & 53,77 \\
\hline CV (\%) & 2,39 & 3,70 & 8,80 & 16,91 & 3,03 & 4,85 & 7,46 & 11,30 \\
Média & 94,10 & 90,64 & 14,54 & 87,72 & 97,27 & 8,21 & 65,69 & 64,88 \\
\hline ns , não significativo, ** e *, significativo a 1\% e 5\% de probabilidade, respectivamente, pelo teste F. ${ }^{n s}$, not \\
significant, ** and *, significant at 1\% and 5\% probability, respectively, by the test F. \\
Fonte: Autoria própria. Own authorship.
\end{tabular}


Os resultados dos testes de vigor das sementes evidenciam que as cultivares apresentaram desempenhos diferentes entre os locais quanto ao potencial fisiológico, havendo, portanto, variações de aptidão para produção de sementes de qualidade entre os ambientes estudados. Luche et al. (2013) também verificaram contraste significativo entre genótipos de aveia branca e anos de cultivo.

De acordo com os dados meteorológicos apresentados na Figura 1, verifica-se que as precipitações pluviais durante os ciclos das plantas cultivadas em Mauá as Serra, Ponta Grossa e Londrina foram de $637 \mathrm{~mm}, 606 \mathrm{~mm}$ e $623 \mathrm{~mm}$, respectivamente. Estes volumes de chuva atenderam o mínimo requerido pela cultura, sem ocorrência de períodos de restrição hídrica. Com relação a temperatura, constatou-se que Mauá da Serra e Ponta Grossa apresentaram maior quantidade de dias com temperaturas mais baixas em relação à Londrina, provavelmente devido a maior altitude desses locais. Quanto as altas temperaturas, os maiores valores foram atingidos nos dias que antecederam a colheita para os três locais, não comprometendo o desenvolvimento das sementes (Figura 1).

As sementes de aveia branca granífera cultivadas em Londrina apresentaram melhores porcentagens de germinação para a maioria das cultivares, sendo desfavorável apenas para a cultivar URS Corona, a qual apresentou maior germinação quando produzida em Ponta Grossa. As cultivares IPR Artemis, URS Taura, e URS Tarimba em Ponta Grossa e IPR Afrodite, URS Charrua e URS Altiva em Mauá da Serra, não diferiram estatisticamente das produzidas em Londrina quanto a germinação (Tabela 2). Resultados semelhantes foram observados por Oliveira et al. (2014), que verificaram superioridade da germinação das sementes de aveia branca granífera produzidas em Londrina, na safra de 2011, quando comparadas as produzidas em Mauá da Serra.

Tabela 2. Germinação de sementes de cultivares de aveia branca granífera produzidas em Mauá da Serra, Ponta Grossa e Londrina, Paraná. Germination of seeds of cultivars of graniferous white oats produced in Mauá da Serra, Ponta Grossa and Londrina, Paraná.

\begin{tabular}{cccc}
\hline \multirow{2}{*}{ Cultivar } & Mauá da Serra & Ponta Grossa & Londrina \\
\cline { 2 - 4 } & ----------- & Germinação $(\%)$ & -------- \\
\hline IPR Afrodite & $96 \mathrm{Aa}$ & $88 \mathrm{Bb}$ & $97 \mathrm{Aa}$ \\
IPR Artemis & $92 \mathrm{Cb}$ & $94 \mathrm{Aab}$ & $97 \mathrm{Aa}$ \\
URS Taura & $93 \mathrm{Bb}$ & $96 \mathrm{Aab}$ & $98 \mathrm{Aa}$ \\
URS Tarimba & $90 \mathrm{Cb}$ & $94 \mathrm{Aa}$ & $96 \mathrm{Aa}$ \\
URS Charrua & $98 \mathrm{Aa}$ & $87 \mathrm{Bb}$ & $97 \mathrm{Aa}$ \\
URS Corona & $88 \mathrm{Cb}$ & $97 \mathrm{Aa}$ & $92 \mathrm{Bb}$ \\
URS Guará & $88 \mathrm{Cc}$ & $92 \mathrm{Ab}$ & $98 \mathrm{Aa}$ \\
URS Altiva & $98 \mathrm{Aa}$ & $89 \mathrm{Bb}$ & $97 \mathrm{Aa}$ \\
\hline
\end{tabular}

C.V. (\%) 2,39

Médias seguidas pela mesma letra minúscula, na linha, não diferem entre si pelo teste de Tukey e, na coluna, letras maiúsculas iguais não diferem entre si pelo teste de Scott-Knott, a 5\% de probabilidade. Means followed by the same lowercase letter in the line do not differ by Tukey test, and in the column, same capital letters do not differ by Scott-Knott's test, at $5 \%$ probability.

Fonte: Autoria própria. Own authorship. 
Independentemente do local de produção, os lotes de sementes apresentaram porcentagem de germinação acima dos $80 \%$, padrão mínimo preconizado para comercialização (BRASIL, 2013). Todavia, esse teste é conduzido em condições controladas de umidade, temperatura e oxigênio, permitindo a semente expressar potencial máximo em gerar plântulas normais. Dessa maneira, elevados resultados de germinação nem sempre indicam elevado potencial de desempenho das sementes, sendo necessária a realização de testes de vigor para identificação mais precisa do potencial fisiológico entre os diferentes lotes de sementes quanto ao maior potencial de armazenamento e performance no campo (MENDONÇA et al., 2014).

A primeira contagem de germinação, comprimento de plântula, massa seca da plântula, velocidade de germinação e a emergência das plântulas são testes de vigor baseados no desempenho das plântulas quanto a uniformidade e a velocidade de emergência. Quanto maior o vigor da semente, mais rápidos são o metabolismo das reservas, a germinação e o estabelecimento em diferentes condições edafoclimáticas (MARCOS FILHO, 2015).

A primeira contagem de germinação foi superior em Londrina para a maioria das cultivares, exceto para URS Corona e URS Guará. A URS Taura, URS Tarimba, URS Corona e URS Guará em Ponta Grossa e URS Charrua e URS Altiva em Mauá da Serra não diferiram de Londrina, indicando uma maior estabilidade para esta característica nos diferentes ambientes. Dentre as cultivares, foi observado pior desempenho para URS Charrua em Ponta Grossa, e URS Tarimba, URS Corona e URS Guará em Mauá da Serra (Tabela 3). Esta divergência nos resultados entre locais e cultivares está diretamente relacionado a adaptabilidade e estabilidade dos genótipos nos diferentes ambientes (BENIN et al., 2005), características estas herdadas dos parentais.

Tabela 3. Primeira contagem da germinação de sementes de cultivares de aveia branca granífera produzidas em Mauá da Serra, Ponta Grossa e Londrina, Paraná. First count of the germination of seeds of cultivars of graniferous white oats produced in Mauá da Serra, Ponta Grossa and Londrina, Paraná.

\begin{tabular}{cccc}
\hline \multirow{2}{*}{ Cultivar } & Mauá da Serra & Ponta Grossa & \multicolumn{1}{c}{ Londrina } \\
\cline { 2 - 4 } & ------ Primeira contagem da germinação (\%) & ------ \\
\hline IPR Afrodite & $89 \mathrm{Bb}$ & $85 \mathrm{Cb}$ & $94 \mathrm{Aa}$ \\
IPR Artemis & $89 \mathrm{Bb}$ & $88 \mathrm{Bb}$ & $97 \mathrm{Aa}$ \\
URS Taura & $87 \mathrm{Bb}$ & $93 \mathrm{Aa}$ & $96 \mathrm{Aa}$ \\
URS Tarimba & $85 \mathrm{Cb}$ & $92 \mathrm{Aa}$ & $97 \mathrm{Aa}$ \\
URS Charrua & $94 \mathrm{Aa}$ & $80 \mathrm{Db}$ & $97 \mathrm{Aa}$ \\
URS Corona & $84 \mathrm{Cb}$ & $95 \mathrm{Aa}$ & $90 \mathrm{Ba}$ \\
URS Guará & $83 \mathrm{Cb}$ & $88 \mathrm{Bab}$ & $92 \mathrm{Ba}$ \\
URS Altiva & $95 \mathrm{Aa}$ & $85 \mathrm{Cb}$ & $97 \mathrm{Aa}$ \\
\hline C.V. $\%$ \% & 3,70 & &
\end{tabular}

Médias seguidas pela mesma letra minúscula, na linha, não diferem entre si pelo teste de Tukey e, na coluna, letras maiúsculas iguais não diferem entre si pelo teste de Scott-Knott, a 5\% de probabilidade. Means followed by the same lowercase letter in the line do not differ by Tukey test, and in the column, same capital letters do not differ by Scott-Knott's test, at 5\% probability.

Fonte: Autoria própria. Own authorship. 
Os testes de comprimento e de massa seca de plântula visam determinar o vigor de sementes por meio da mensuração do comprimento médio e do acúmulo de massa seca das plântulas normais, respectivamente, formadas sob condições controladas de ambiente. As sementes mais vigorosas transformam e mobilizam de maneira mais eficiente as reservas dos tecidos de armazenamento para o eixo embrionário, o qual apresenta maior capacidade de incorporação dessas reservas, características que favorecem o rápido crescimento e acúmulo de massa pelas plântulas (MARCOS FILHO, 2015). As sementes oriundas do cultivo em Londrina apresentaram plântulas com maior comprimento, entretanto, não diferiram dos materiais IPR Afrodite, URS Taura, URS Charrua, URS Corona e URS Guará em Ponta Grossa e URS Altiva em Mauá da Serra. Em Londrina e Ponta Grossa, os materiais URS Corona e URS Altiva apresentaram os menores comprimentos de plântula, divergindo apenas das cultivares IPR Artemis e URS Taura. Em Mauá da Serra, as cultivares IPR Afrodite e URS Corona apresentaram os menores valores para esta característica (Tabela 4).

Tabela 4. Comprimento de plântula de cultivares de aveia branca granífera produzidas em Mauá da Serra, Ponta Grossa e Londrina, Paraná. Length of seedlings of graniferous white oats cultivars produced in Mauá da Serra, Ponta Grossa and Londrina, Paraná.

\begin{tabular}{cccc}
\hline \multirow{2}{*}{ Cultivar } & Mauá da Serra & Ponta Grossa & Londrina \\
\cline { 2 - 4 } & ------- Comprimento de plântula $(\mathrm{cm})$ & -------- \\
\hline IPR Afrodite & $6,6 \mathrm{Db}$ & $16,3 \mathrm{Aa}$ & $18,4 \mathrm{Aa}$ \\
IPR Artemis & $15,4 \mathrm{Ab}$ & $13,4 \mathrm{Bb}$ & $17,8 \mathrm{Aa}$ \\
URS Taura & $11,0 \mathrm{Bb}$ & $15,7 \mathrm{Aa}$ & $15,1 \mathrm{Ba}$ \\
URS Tarimba & $8,3 \mathrm{Cc}$ & $16,2 \mathrm{Ab}$ & $19,3 \mathrm{Aa}$ \\
URS Charrua & $12,2 \mathrm{Bb}$ & $18,1 \mathrm{Aa}$ & $18,3 \mathrm{Aa}$ \\
URS Corona & $7,2 \mathrm{Db}$ & $14,4 \mathrm{Ba}$ & $15,5 \mathrm{Ba}$ \\
URS Guará & $11,5 \mathrm{Bb}$ & $16,9 \mathrm{Aa}$ & $18,2 \mathrm{Aa}$ \\
URS Altiva & $13,8 \mathrm{Aab}$ & $13,5 \mathrm{Bb}$ & $15,8 \mathrm{Ba}$ \\
\hline C.V. $(\%)$ & 8,80 & &
\end{tabular}

Médias seguidas pela mesma letra minúscula, na linha, não diferem entre si pelo teste de Tukey e, na coluna, letras maiúsculas iguais não diferem entre si pelo teste de Scott-Knott, a 5\% de probabilidade. Means followed by the same lowercase letter in the line do not differ by Tukey test, and in the column, same capital letters do not differ by Scott-Knott's test, at 5\% probability.

Fonte: Autoria própria. Own authorship.

Em Londrina, todas as cultivares apresentaram plântulas com elevado acúmulo de massa seca, não diferindo dos materiais URS Taura, URS Charrua e URS Altiva em Ponta Grossa, e URS Taura e URS Altiva em Mauá da Serra. Em Londrina, a cultivar que apresentou o menor valor para este caractere foi a URS Taura, enquanto que em Ponta Grossa foram as cultivares IPR Artemis, URS Taura, URS Tarimba e URS Corona. Em Mauá da Serra, as cultivares IPR Afrodite, URS Tarimba e URS Corona apresentaram os menores valores para a variável em questão (Tabela 5).

Para índice de velocidade de emergência verificou-se que, em Londrina, todas as cultivares apresentaram elevados valores para esta característica (Tabela 6), o que demonstra que as condições ambientais, de forma geral, foram benéficas para a produção de sementes de elevado vigor (Figura 1). Este fato favorece uma emergência rápida e uniforme das sementes, 
beneficiando o estabelecimento do estande, o crescimento inicial das plântulas, o que proporciona o desenvolvimento das plantas e resulta em maior tolerância a condições estressantes do ambiente (CARVALHO; NAKAGAWA, 2012). As cultivares URS Tarimba e URS Charrua em Ponta Grossa e Mauá da Serra apresentaram qualidade de sementes inferior quando comparadas as produzidas em Londrina para esta variável.

Tabela 5. Massa seca de plântulas de cultivares de aveia branca granífera produzidas em Mauá da Serra, Ponta Grossa e Londrina, Paraná. Dry mass of seedlings of graniferous white oats cultivars produced in Mauá da Serra, Ponta Grossa and Londrina, Paraná.

\begin{tabular}{|c|c|c|c|}
\hline \multirow{2}{*}{ Cultivar } & Mauá da Serra & Ponta Grossa & Londrina \\
\hline & \multicolumn{3}{|c|}{--_-_-- Massa seca de plântula (mg) --_---- } \\
\hline IPR Afrodite & $38,0 \mathrm{Bc}$ & $88,3 \mathrm{Ab}$ & $114,5 \mathrm{Aa}$ \\
\hline IPR Artemis & $74,3 \mathrm{Ab}$ & $65,3 \mathrm{Bb}$ & $123,5 \mathrm{Aa}$ \\
\hline URS Taura & $69,0 \mathrm{Aa}$ & $66,3 \mathrm{Ba}$ & $82,3 \mathrm{Ba}$ \\
\hline URS Tarimba & $50,8 \mathrm{Bc}$ & $77,8 \mathrm{Bb}$ & $123,8 \mathrm{Aa}$ \\
\hline URS Charrua & $86,5 \mathrm{Ab}$ & $103,5 \mathrm{Aab}$ & $122,0 \mathrm{Aa}$ \\
\hline URS Corona & $37,0 \mathrm{Bc}$ & $76,0 \mathrm{Bb}$ & $113,8 \mathrm{Aa}$ \\
\hline URS Guará & $78,5 \mathrm{Ab}$ & $89,0 \mathrm{Ab}$ & $123,3 \mathrm{Aa}$ \\
\hline URS Altiva & $91,5 \mathrm{Aa}$ & $96,8 \mathrm{Aa}$ & $114,0 \mathrm{Aa}$ \\
\hline C.V. (\%) & 16,91 & & \\
\hline
\end{tabular}

Médias seguidas pela mesma letra minúscula na linha não diferem entre si pelo teste de Tukey e, na coluna, letras maiúsculas iguais não diferem entre si pelo teste de Scott-Knott, a 5\% de probabilidade. Means followed by the same lowercase letter in the line do not differ by Tukey test, and in the column, same capital letters do not differ by Scott-Knott's test, at $5 \%$ probability.

Fonte: Autoria própria. Own authorship.

Tabela 6. Índice de velocidade de emergência de plântulas de sementes de cultivares de aveia branca granífera produzidas em Mauá da Serra, Ponta Grossa e Londrina, Paraná. Seedling emergence speed index of graniferous white oats cultivars produced in Mauá da Serra, Ponta Grossa and Londrina, Paraná.

\begin{tabular}{cccc}
\hline \multirow{2}{*}{ Cultivar } & Mauá da Serra & Ponta Grossa & \multicolumn{1}{c}{ Londrina } \\
\cline { 2 - 4 } & ----- Índice de velocidade de emergência $(\%)$ & ----- \\
\hline IPR Afrodite & $8,2 \mathrm{Aa}$ & $7,7 \mathrm{Ba}$ & $8,4 \mathrm{Ba}$ \\
IPR Artemis & $8,3 \mathrm{Aa}$ & $8,0 \mathrm{Aa}$ & $8,1 \mathrm{Ba}$ \\
URS Taura & $7,8 \mathrm{Aa}$ & $7,5 \mathrm{Ba}$ & $8,1 \mathrm{Ba}$ \\
URS Tarimba & $8,2 \mathrm{Ab}$ & $8,2 \mathrm{Ab}$ & $8,9 \mathrm{Aa}$ \\
URS Charrua & $7,9 \mathrm{Ac}$ & $8,6 \mathrm{Ab}$ & $9,4 \mathrm{Aa}$ \\
URS Corona & $8,1 \mathrm{Aa}$ & $8,1 \mathrm{Aa}$ & $8,3 \mathrm{Ba}$ \\
URS Guará & $8,2 \mathrm{Aa}$ & $8,2 \mathrm{Aa}$ & $8,7 \mathrm{Ba}$ \\
URS Altiva & $8,0 \mathrm{Aa}$ & $7,9 \mathrm{Ba}$ & $8,4 \mathrm{Ba}$ \\
\hline
\end{tabular}

C.V. $(\%) \quad 4,85$

\footnotetext{
Médias seguidas pela mesma letra minúscula na linha não diferem entre si pelo teste de Tukey e, na coluna, letras maiúsculas iguais não diferem entre si pelo teste de Scott-Knott, a 5\% de probabilidade. Means followed by the same lowercase letter in the line do not differ by Tukey test, and in the column, same capital letters do not differ by Scott-Knott's test, at 5\% probability.

Fonte: Autoria própria. Own authorship.
} 
Em Londrina e Mauá da Serra observaram-se melhores resultados de emergência de plântulas (Tabela 7), indicando o maior vigor das sementes provenientes desses locais devido ao maior percentual das sementes em emergir do substrato e formar plântulas normais, conforme descrito por Oliveira et al. (2009). Apesar da elevada porcentagem de emergência de plântulas, o menor desempenho para essa variável foi em Ponta Grossa, provavelmente devido à maior ocorrência de precipitação pluvial próxima a colheita das sementes nesse local (Figura 1).

Tabela 7. Emergência de plântulas em areia de cultivares de aveia branca granífera produzidas em Mauá da Serra, Ponta Grossa e Londrina, Paraná. Emergence of seedlings in sand of cultivars of graniferous white oats produced in Mauá da Serra, Ponta Grossa and Londrina, Paraná.

\begin{tabular}{cccc}
\hline Mauá da Serra & Ponta Grossa & Londrina & C.V. (\%) \\
\hline- & 96 b & 98 a & 3,03 \\
\hline 98 a & &
\end{tabular}

Médias seguidas pela mesma letra na linha não diferem entre si pelo teste de Tukey, a 5\% de probabilidade. Means followed by the same letter in the line do not differ by Tukey test, at 5\% probability.

Fonte: Autoria própria. Own authorship.

Vigano et al. (2010) atribuíram a redução da qualidade fisiológica de sementes de trigo ao excesso de chuvas na ocasião da colheita. De acordo com Teixeira Filho et al. (2010), chuvas sobre a cultura em estádio maduro podem explicar a redução da qualidade das sementes, devido à elevada intensidade respiratória, associada ao consumo das reservas acumuladas, induzidas devido a absorção de água pelas sementes logo depois de completada a maturação (FRANCESCHI et al., 2009).

Tabela 8. Envelhecimento acelerado de sementes de cultivares de aveia branca granífera produzidas em Mauá da Serra, Ponta Grossa e Londrina, Paraná. Accelerated aging of seeds of graniferous white oat cultivars produced in Mauá da Serra, Ponta Grossa and Londrina, Paraná.

\begin{tabular}{cccc}
\hline \multirow{2}{*}{ Cultivar } & Mauá da Serra & Ponta Grossa & Londrina \\
\cline { 2 - 4 } & -------- Envelhecimento acelerado (\%) & ------- \\
\hline IPR Afrodite & $72 \mathrm{Ba}$ & $74 \mathrm{Ba}$ & $58 \mathrm{Bb}$ \\
IPR Artemis & $72 \mathrm{Bb}$ & $84 \mathrm{Aa}$ & $76 \mathrm{Aab}$ \\
URS Taura & $48 \mathrm{~Eb}$ & $79 \mathrm{Aa}$ & $30 \mathrm{Dc}$ \\
URS Tarimba & $64 \mathrm{Ca}$ & $12 \mathrm{Cc}$ & $38 \mathrm{Cb}$ \\
URS Charrua & $57 \mathrm{Db}$ & $71 \mathrm{Ba}$ & $73 \mathrm{Aa}$ \\
URS Corona & $71 \mathrm{Ba}$ & $78 \mathrm{Aa}$ & $61 \mathrm{Bb}$ \\
URS Guará & $80 \mathrm{Aa}$ & $76 \mathrm{Ba}$ & $78 \mathrm{Aa}$ \\
URS Altiva & $65 \mathrm{Cb}$ & $75 \mathrm{Ba}$ & $81 \mathrm{Aa}$ \\
\hline
\end{tabular}

C.V. (\%) 7,46

Médias seguidas pela mesma letra minúscula na linha não diferem entre si pelo teste de Tukey e, na coluna, letras maiúsculas iguais não diferem entre si pelo teste de Scott-Knott, a 5\% de probabilidade. Means followed by the same lowercase letter in the line do not differ by Tukey test, and in the column, same capital letters do not differ by Scott-Knott's test, at 5\% probability.

Fonte: Autoria própria. Own authorship. 
O teste de envelhecimento acelerado baseia-se na resposta da semente após sua exposição, por determinado tempo, à temperatura e umidade relativa elevadas, principais fatores ambientais que causam sua deterioração. Sementes com maior vigor apresentam maior capacidade de produzir plântulas normais e de porcentagem de germinação mais elevada em relação as de menor vigor após submissão ao teste de envelhecimento acelerado (SOUZA et $a l .$, 2009). Pelo teste de envelhecimento acelerado verificou-se que as sementes da cultivar URS Tarimba oriundas de Ponta Grossa apresentaram menor porcentagem de plântulas normais no teste germinação.

Em Mauá da Serra e Londrina, os menores valores para este caractere foram observados para a cultivar URS Taura. Estes resultados permitem inferir que os ambientes de produção afetaram de maneira distinta o vigor dos lotes de sementes, e que, os genótipos possuem papel importante na tolerância aos estresses abióticos (Tabela 8). Minuzzi et al. (2010) observaram resultados de germinação, após o teste de envelhecimento acelerado, diferentes entre cultivares produzidas em um mesmo ambiente, fortalecendo a inferência de que o vigor está intimamente relacionado a base genética de cada cultivar.

Tabela 9. Condutividade elétrica de sementes de cultivares de aveia branca granífera produzidas em Mauá da Serra, Ponta Grossa e Londrina, Paraná. Electric conductivity of seeds of cultivars of graniferous white oats produced in Mauá da Serra, Ponta Grossa and Londrina, Paraná.

\begin{tabular}{cccc}
\hline \multirow{2}{*}{ Cultivar } & Mauá da Serra & Ponta Grossa & Londrina \\
\cline { 2 - 4 } & \multicolumn{2}{c}{ Condutividade elétrica $\left(\mu \mathrm{cm}^{-1} \cdot \mathrm{g}^{-1}\right)$} \\
\hline IPR Afrodite & $81,44 \mathrm{Aa}$ & $63,25 \mathrm{Ab}$ & $86,01 \mathrm{Aa}$ \\
IPR Artemis & $88,60 \mathrm{Aa}$ & $55,89 \mathrm{Ab}$ & $66,53 \mathrm{Bb}$ \\
URS Taura & $67,83 \mathrm{Ba}$ & $54,86 \mathrm{Ab}$ & $69,59 \mathrm{Ba}$ \\
URS Tarimba & $59,82 \mathrm{Ca}$ & $39,52 \mathrm{Bb}$ & $62,31 \mathrm{Ba}$ \\
URS Charrua & $67,39 \mathrm{Bb}$ & $49,39 \mathrm{Bc}$ & $81,17 \mathrm{Aa}$ \\
URS Corona & $71,23 \mathrm{Bab}$ & $59,85 \mathrm{Ab}$ & $82,39 \mathrm{Aa}$ \\
URS Guará & $67,00 \mathrm{Ba}$ & $47,58 \mathrm{Bb}$ & $68,88 \mathrm{Ba}$ \\
URS Altiva & $55,90 \mathrm{Cb}$ & $40,66 \mathrm{Bc}$ & $70,22 \mathrm{Ba}$ \\
\hline
\end{tabular}

C.V. (\%) 11,30

Médias seguidas pela mesma letra minúscula na linha não diferem entre si pelo teste de Tukey e, na coluna, letras maiúsculas iguais não diferem entre si pelo teste de Scott-Knott, a 5\% de probabilidade. Means followed by the same lowercase letter in the line do not differ by Tukey test, and in the column, same capital letters do not differ by Scott-Knott's test, at 5\% probability.

Fonte: Autoria própria. Own authorship.

Quanto ao teste de condutividade elétrica, em Mauá da Serra, as sementes das cultivares URS Tarimba e URS Altiva apresentaram os menores valores, indicando melhor qualidade das sementes para essa variável. Em Ponta Grossa, as menores condutividades elétricas foram das cultivares URS Tarimba, URS Charrua, URS Guará e URS Altiva. E em Londrina, IPR Artemis URS Taura URS Tarimba, URS Guará e URS Altiva apresentaram os menores valores para essa variável (Tabela 9). A condutividade elétrica é um teste eficiente, rápido e de fácil execução para determinação do vigor do potencial fisiológico da aveia branca, em que a qualidade das sementes é avaliada de forma indireta por meio da determinação da 
quantidade de lixiviados na solução de embebição das sementes. Os menores valores, representam uma menor liberação de solutos como açúcares, aminoácidos, proteínas e íons inorgânicos na solução, indicando maior potencial fisiológico das sementes pela maior organização e integridade das membranas celulares (SPONCHIADO et al., 2014).

Considerando os locais de produção, enquanto as sementes da cultivar IPR Artemis apresentaram maior potencial fisiológico em Ponta Grossa e Londrina, as sementes das cultivares URS Corona e URS Altiva foram melhores em Ponta Grossa do que em Londrina. E as cultivares IPR Afrodite, URS Taura, URS Tarimba, URS Charrua e URS Guará apresentaram maior desempenho para essa variável em Ponta Grossa (Tabela 9).

De uma forma geral, os resultados evidenciaram que Londrina foi o local que favoreceu a produção de sementes de melhor qualidade fisiológica para a maioria dos genótipos avaliados, quando comparado a Mauá da Serra e Ponta Grossa. Estes resultados corroboram os de Oliveira et al. (2014), os quais concluíram que Londrina possibilitou a produção de sementes com maior qualidade fisiológica que Mauá da Serra para a safra de 2011.

A diferença de germinação e vigor entre as cultivares dentro de um mesmo local de produção está atrelado, em grande parte, as seleções realizadas dentro dos programas de melhoramento. Segundo Cardoso et al. (2009), a qualidade fisiológica das sementes de um genótipo é decorrente das escolhas dos progenitores. Dessa forma, deve haver uma maior atenção dentro dos programas de melhoramento para a utilização de progenitores com maior estabilidade quanto a produção de sementes de aveia branca granífera com alta qualidade fisiológica, bem como a definição de locais aptos para produção de sementes de cultivares específicas.

\section{CONCLUSÃO}

Londrina, Ponta Grossa e Mauá da Serra apresentam potencial para a produção de sementes de aveia branca granífera, resultando em sementes com germinação acima dos padrões de comercialização da espécie.

O cultivo em Londrina resulta na produção de sementes de elevado vigor para a maioria das cultivares analisadas. Já em Ponta Grossa, as sementes de melhor qualidade foram produzidas pelas cultivares URS Taura, URS Corona e URS Guará, e em Mauá da Serra pela cultivar URS Altiva.

\section{AGRADECIMENTOS}

O presente trabalho foi realizado com apoio da Coordenação de Aperfeiçoamento de Pessoal de Nível Superior - Brasil (CAPES) - Código de Financiamento 001.

\section{REFERÊNCIAS BIBLIOGRÁFICAS}

ANDON, M. B.; ANDERSON, J. W. A. The oatmeal-cholesterol connection: 10 years later. American Journal of Lifestyle Medicine, Thousand Oaks, v. 2, n. 1, p.51-57, 2008. 
Disponível em: http://journals.sagepub.com/doi/pdf/10.1177/1559827607309130. Acesso em: 10 set. 2018.

BENIN, G.; DE CARVALHO, F. I. F.; OLIVEIRA, A. C.; LORENCETTI, C.; VIEIRA, E. A.; COIMBRA, J. L. M.; SILVA, G. O. Adaptabilidade e estabilidade em aveia em ambientes estratificados. Ciência Rural, Santa Maria, v. 35, n. 2, p.295-302, 2005. Disponível em: http://www.scielo.br/pdf/\%0D/cr/v35n2/a08v35n2.pdf. Acesso em: 10 set. 2018.

BHERING, S. B.; SANTOS, H. G. Mapa de solos do estado do Paraná: legenda atualizada. Rio de Janeiro: Embrapa Solos; Curitiba: Embrapa Florestas; Londrina: IAPAR, 2008. 73 p. Disponível em: http://www.infoteca.cnptia.embrapa.br/infoteca/handle/doc/339505. Acesso em: 28 set. 2018.

BRASIL. Ministério da Agricultura, Pecuária e Abastecimento. Instrução normativa $\mathrm{n}^{\circ}$ 45, de 17 de setembro de 2013. Padrões de identidade e qualidade para a produção e a comercialização de sementes. Diário Oficial da União, Brasília, DF 20 set. 2013, Seção 1, p. 7-8. Disponível em: http://www.agricultura.gov.br/assuntos/insumos-agropecuarios/insumosagricolas/sementes-e-mudas/legislacao. Acesso em: 25 set. 2018.

BRASIL. Ministério da Agricultura, Pecuária e Abastecimento. Secretaria de Defesa Agropecuária. Regras para análise de sementes. Brasília: MAPA/ACS, 2009. 395 p. Disponível em: http://www.agricultura.gov.br/arq_editor/file/2946_regras_analise_sementes.pdf. Acesso em: 30 set. 2018.

BUTT, M. S.; TAHIR-NADEEM, M.; KHAN, M. K. I.; SHABIR, R.; BUTT, M. S. Oat: unique among the cereals Oat: unique among the cereals. European journal of nutrition, Heidelberg, v. 47, n. 2, p.68-79, 2008. Disponível em: https://www.researchgate.net/profile/Muhammad_Khan211/publication/5550398_Oat_Uniqu e_among_the_cereals/links/02e7e539bd282c3f24000000/Oat-Unique-among-the-cereals.pdf. Acesso em: 10 set. 2018.

CARDOSO, D. L.; SILVA, R. F.; PEREIRA, M. G.; VIANA, A. P.; ARAÚJO, E. F. Diversidade genética e parâmetros genéticos relacionados à qualidade fisiológica de sementes em germoplasma de mamoeiro. Revista Ceres, Viçosa, v. 56, n. 5, p.572-579, 2009. Disponível em: http://www.redalyc.org/html/3052/305226893008/. Acesso em: 22 set. 2018.

CARVAlHO, N. M.; NACAGAWA, J. Sementes: ciência, tecnologia e produção. 5. ed. Jaboticabal: FUNEP, 2012. 590 p.

LÂNGARO, N. C.; CARVALHO, Q. I. Indicações técnicas para a cultura da aveia. In: REUNIÃO DA COMISSÃO BRASILEIRA DE PESQUISA DE AVEIA, 34, 2014, Passo Fundo. Anais [...] Passo Fundo: UPF, 2014. 136 p. Disponível em: http://editora.upf.br/images/ebook/cultura_aveia.pdf. Acesso em: 23 set. 2018.

COMPANHIA NACIONAL DE ABASTECIMENTO - CONAB. Acompanhamento da Safra de Brasileira: grão. Brasília, 2017. Disponível em: http://www.conab.gov.br/OlalaCMS/uploads/arquivos/17_05_12_10_37_57_boletim_graos_ maio_2017.pdf. Acesso em: 21 out. 2018. 
CRESTANI, M.; CARVALHO, F. I. F.; OLIVEIRA, A. C.; SILVA, J. A. G.; GUTKOSKI, L. C.; SARTORI, J. F; BARBIERI, R. L.; BARETTA, D. Conteúdo de $\beta$-glucana em cultivares de aveia-branca cultivadas em diferentes ambientes. Pesquisa Agropecuária Brasileira, Brasília, v. 45, n.3, p.261-268, 2010. Disponível em: http://www.scielo.br/pdf/pab/v45n3/v45n3a05.pdf. Acesso em: 21 set. 2018.

MORI, C.; SANTOS, R. S. F.; SANTOS, H. P. Aspectos econômicos e conjunturais da cultura da aveia. Embrapa Trigo, 2012. 26 p. Disponível em: http://www.infoteca.cnptia.embrapa.br/bitstream/doc/969145/1/2013documentosonline136.pd f. Acesso em: 15 set. 2018.

FRANCESCHI, L. D.; BENIN, G.; GUARIENTI, E.; MARCHIORO, V. S.; MARTIN, T. N. Fatores pré-colheita que afetam a qualidade tecnológica de trigo. Ciência Rural, Santa Maria, v. 39, n. 5, p.1624-1631, 2009. Disponível em: http://www.scielo.br/scielo.php?pid=S010384782009005000060\&script=sci_abstract\&tlng=pt. Acesso em: 30 set. 2018.

GOMES, G. D. R.; BENIN, G.; ROSINHA, R. C.; GALVAN, D.; PAGLIOSA, E. S.; PINNOW, SILVA, C. L.; BECHE, E. Produção e qualidade fisiológica de sementes de soja em diferentes ambientes de cultivo. Semina Ciências Agrárias, Londrina, v. 33, supl. 1, p.2593-2604, 2012. Disponível em: http://www.redalyc.org/pdf/4457/445744117012.pdf. Acesso em: 2 set. 2018.

HÖFS, A.; SCHUCH, L. O. B.; PESKE, S. T.; BARROS, A. C. S. A. Efeito da qualidade fisiológica das sementes e da densidade de semeadura sobre o rendimento de grãos e qualidade industrial em arroz. Revista Brasileira de Sementes, Londrina, v. 26, n. 2, p.5462, 2004. Disponível em: http://www.scielo.br/scielo.php?pid=S010131222004000200008\&script=sci_abstract\&tlng=pt. Acesso em: 1 set. 2018.

LUCHE, H. S.; NORNBERG, R.; CRESTANI, M.; RIBEIRO, G.; WOYANN, L. G.; SILVA, J. A. G.; OLIVEIRA, A. C. Parameters of adaptability and stability in brazilian and exotic cultivars of white oat. Current Agricultural Science and Technology, Pelotas, v. 19, n. 1, p.31-40, 2013. Disponível em: https://periodicos.ufpel.edu.br/ojs2/index.php/CAST/article /view/2904. Acesso em: 1 set. 2018.

LUDWIG, M. P.; SCHUCH, L. O. B.; LUCCA FILHO, O. A.; AVELAR, S. A. G.; MIELEZRSKI, F.; OLIVEIRA, S.; CRIZEL, R. L. Desempenho de sementes e plantas de milho híbrido originadas de lotes de sementes com alta e baixa qualidade fisiológica. Revista Brasileira de Milho e Sorgo, Sete Lagoas, v. 8 n. 1, p.83-92, 2009. Disponível em: http://rbms.cnpms.embrapa.br/index.php/ojs/article/view/272/pdf175. Acesso em: 5 set. 2018.

MAGUIRE, J. D. Speed of germination-aid in selection and evaluation for seedling emergence and vigor. Crop Science, Madson, v. 2, n.1, p.176-177, 1962. Disponível em: https://dl.sciencesocieties.org/publications/cs/abstracts/2/2/CS0020020176. Acesso em: 1 set. 2018.

MARCOS FILHO, J. Fisiologia de sementes de plantas cultivadas. Londrina: ABRATES, 2015. 660 p. 
MARCOS FILHO, J. Seed vigor testing: an overview of the past, present and future perspective. Scientia Agricola, Piracicaba, v. 72, n. 4, p.363-374, 2015. Disponível em: http://www.scielo.br/scielo.php?pid=S0103-90162015000400363\&script=sci_arttext. Acesso em: 10 dez. 2019.

MARCOS FILHO, J. Teste de envelhecimento acelerado. In: KRZYZANOWSKI, F. C.; VIEIRA, R. D.; FRANÇA-NETO, J. B. (Ed.). Vigor de sementes: conceitos e testes. Londrina: ABRATES, 1999. cap. 3, p.1-24.

MENDONÇA, A. O.; LEMES E. S.; OLIVEIRA, S.; GEHLING, V. M.; PEDROSO, C. E. S. Testes rápidos para avaliação do vigor de sementes de aveia branca. Enciclopédia Biosfera, v. 10, n. 19, p.1742-1753, 2014. Disponível em: http://www.conhecer.org.br/enciclop/2014b/AGRARIAS/testes\%20rapidos.pdf. Acesso em: 10 dez. 2019.

MINUZZI, A.; BRACCINI, A. D. L.; RANGEL, M. A. S.; SCAPIM, C. A.; BARBOSA, M. C.; ALBRECHT, L. P. Qualidade de sementes de quatro cultivares de soja, colhidas em dois locais no Estado do Mato Grosso do Sul. Journal of Seed Science, Londrina, v. 32, n. 1, p.176-185, 2010. Disponível em: http://www.scielo.br/scielo.php?pid=S010131222010000100020\&script=sci_abstract\&tlng=pt. Acesso em: 3 set. 2018.

NAKAGAWA, J. Teste de vigor baseados no desempenho das plântulas. In: KRZYZANOWSKI, F. C.; VIEIRA, R. D.; FRANÇANETO, J. B. Vigor de sementes: conceitos e testes. Londrina: ABRATES, 1999. cap. 2, p. 2.1-2.24.

NERLING, D.; COELHO, C. M. M.; NODARI, R. O. Genetic diversity for physiological quality of seeds from corn (Zea mays L.) intervarietal crossbreeds. Journal of Seed Science, Londrina, v. 35, n. 4, p.449-456, 2013. Disponível em: http://www.scielo.br/scielo.php?script=sci_arttext\&pid=S2317-15372013000400006. Acesso em: 7 set. 2018.

OLIVEIRA, E. A. D. P.; ZUCARELI, C.; FONSECA, I. C. D. B.; OLIVEIRA, J. C. D.; BARROS, A. S. D. R. Foliar fungicide and environments on the physiological quality of oat seeds. Journal of Seed Science, Londrina, v. 36, n. 1, p.15-24, 2014. Disponível em: http://www.scielo.br/scielo.php?script=sci_arttext\&pid=S2317-15372014000100002. Acesso em: 7 set. 2018.

OLIVEIRA, A. C. S.; MARTINS, G. N.; SILVA, R. F.; VIEIRA, H. D. Testes de vigor em sementes baseados no desempenho de plântulas. InterSciencePlace, v. 2, n. 4, p.1-21, 2009. Disponível em: http://intranetdoc.epagri.sc.gov.br/producao_tecnico_cientifica/DOC_2186.pdf. Acesso em: 10 dez. 2019.

SOUZA, S. A. D.; NAKAGAWA, J.; MACHADO, C. G. Teste de envelhecimento acelerado em sementes de aveia preta. Revista Brasileira de Sementes, Londrina, p. 155-163, 2009. Disponível em: http://www.scielo.br/pdf/rbs/v31n2/v31n2a18.pdf. Acesso em: 1 set. 2018.

SPONCHIADO, J. C.; SOUZA, C. A.; COELHO, C. M. M. este de condutividade elétrica para determinação do potencial fisiológico de sementes de aveia branca. Semina, v. 35, n. 4, 
p.2405-2414, 2014. Disponível em: https://www.redalyc.org/pdf/4457/445744143014.pdf. Acesso em: 10 dez. 2019.

TEIXEIRA FILHO, M. C. M. T.; BUZETTI, S.; ANDREOTTI, M.; ARF, O.; BENETT. C. G. S. Doses, fontes e épocas de aplicação de nitrogênio em trigo irrigado em plantio direto. Pesquisa Agropecuária Brasileira, Brasília, v. 45, n. 8, p.797-804, 2010. Disponível em: http://www.scielo.br/pdf/pab/v45n8/v45n8a04.pdf. Acesso em: 1 set. 2018.

VIEIRA, R. D.; KRZYZANOWSKI, F. C. Teste de condutividade elétrica. In: KRZYZANOWSKI, F. C.; VIEIRA, R. D.; FRANÇA-NETO, J. B. (Ed.). Vigor de sementes: conceitos e testes. Londrina: ABRATES, 1999. cap. 4, p.1-26.

VIGANO, J.; BRACCINI, A. L.; SCAPIM, C. A.; FRANCO, F. A.; SCHUSTER, I.; MOTERLE, L. M.; TEXEIRA, L. Qualidade fisiológica de sementes de trigo em resposta aos efeitos de anos e épocas de semeadura. Journal of Seed Science, Londrina, v. 32, n. 3, p. 8696, 2010. Disponível em: http://www.scielo.br/pdf/rbs/v32n3/v32n3a10.pdf. Acesso em: 10 set. 2018. 